\title{
Cultural Difference and Adaptation of Communication Styles in Computer-Mediated Group Brainstorming
}

\author{
Hao-Chuan Wang ${ }^{1}$, Susan R. Fussell ${ }^{1,2}$, Leslie D. Setlock ${ }^{2}$ \\ ${ }^{1}$ Information Science, ${ }^{2}$ Department of Communication \\ Cornell University \\ Ithaca, NY 14850 USA \\ [hw346, sfussell, lds87]@cornell.edu
}

\begin{abstract}
Supporting creativity via collaborative group brainstorming is a prevalent practice in organizations. Today's technology makes it easy for international and intercultural group members to brainstorm together remotely, but surprisingly little is known about how culture and medium shape the underlying brainstorming process. In a laboratory study, we examined the influences of individual cultural background (American versus Chinese), group cultural composition (same- versus mixed-culture groups), and communication medium (text-only versus video-enabled chatrooms) on group brainstorming conversations. Cultural differences and adaptation in conversational talkativeness and responsiveness were identified. The text-only medium reduced cultural differences in talkativeness. Working in a mixed-culture group led to cultural adaptation in the communication style of Chinese but not American participants. We discuss implications for international group brainstorming.
\end{abstract}

\section{Author Keywords}

Cross-cultural communication, group brainstorming, computer-mediated communication, group creativity

\section{ACM Classification Keywords}

H5.3 Group and Organization Interface: Computersupported cooperative work

\section{INTRODUCTION}

Brainstorming, or generating new ideas to approach a situation or stimulus, is a fundamental aspect of many types of work. Designers brainstorm new products, researchers brainstorm study ideas, and engineers brainstorm different solutions to construction problems. Because individuals are often limited in their visions or cognitive resources, a popular way to support creativity and innovation in

Permission to make digital or hard copies of all or part of this work for personal or classroom use is granted without fee provided that copies are not made or distributed for profit or commercial advantage and that copies bear this notice and the full citation on the first page. To copy otherwise, or republish, to post on servers or to redistribute to lists, requires prior specific permission and/or a fee.

CHI 2009, April 4-9, 2009, Boston, Massachusetts, USA.

Copyright 2009 ACM 978-1-60558-246-7/09/04...\$5.00. organizations is to brainstorm and generate ideas collaboratively [36].

During group brainstorming, group members are expected to think of as many ideas as possible even if the ideas seem wild or deviant. The main purpose of asking people to brainstorm together is to stimulate more creative thoughts by overhearing other group members' ideas [34]. (See Figure 1 for an example of a brainstorming task from our experiment).

The wide availability of computer-mediated communication (CMC) technologies makes it easy for geographically dispersed group members to brainstorm remotely and interculturally, but little is known about how culture affects the processes and quality of computer-mediated group brainstorming. Recent research has shown interactions between culture and communication media on collaborative work (e.g., [12][38][40][45]). For example, Chinese pairs engage in more in depth conversations when rank ordering items than do American pairs, and these cultural differences are heightened when the pairs communicate face-to-face vs. via Instant Messaging [38]. These and similar findings suggest that the technology used for brainstorming will interact with individual cultural background to shape group communication processes.

Previous studies of culture and CMC have typically used tasks such as direction-giving [12][45] or rank ordering items [38][40] that have, at least in principle, one correct solution. Group brainstorming differs from such tasks along

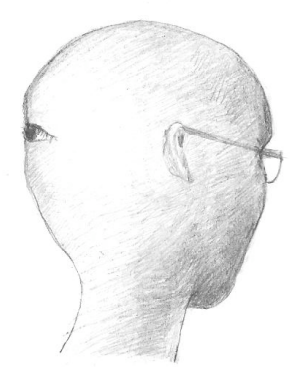

Figure 1. The "Extra Eye" brainstorming task used in our study. Participants were asked, "What are the benefits and difficulties if people had an third eye in the future?" 
a number of dimensions. In particular, group brainstorming aims to elicit as many ideas as possible through social interaction. Creative, unconventional and even deviant ideas are all encouraged. The structure of group brainstorming is different from tasks that look for correct solutions, and therefore the ways culture and communication media influence group brainstorming may also be different. As people's behavior during group brainstorming is affected by peer evaluation and social conformity [1][13], culture and media may influence the extent of evaluation pressure people perceive and change the dynamics of group brainstorming.

In the current study, we examine how team members' national cultural background (American vs. Chinese), group cultural composition (same- versus mixed-culture groups), and communication medium (text-only vs. video-enabled chatrooms) influence communication in a brainstorming task. In this study, three-person intra- or intercultural groups were asked to brainstorm over two communication media: a richer medium (video-enabled chatroom) and a leaner medium (text-only chatroom). The results indicate that Chinese-born participants were less talkative than American-born participants, but this difference was reduced when the triads interacted over the leaner text-only medium. We found evidence of cultural adaptation in mixed-culture groups, such that Chinese-born participants adapted their communication styles when working with American partners.

\section{THEORETICAL BACKGROUND}

We first describe the characteristics of group brainstorming tasks; then, we review research in three areas pertinent to the current study: dimensions of cultural variation, influences of group cultural composition and effects of communication medium.

\section{Group Brainstorming}

Group brainstorming is typically conducted according to a set of rules intended to facilitate the generation of ideas in groups [36]. Brainstorming rules primarily emphasize the quantity of ideas and discourage criticism. The assumption is that more ideas will be stimulated if group members can overhear one another's ideas and that people will be more likely to express unconventional ideas if they do not have to worry about others' negative evaluations.

In the literature on creativity, one prominent observation is the vulnerability of group creativity to social factors [1]. Consistent with this observation, considerable research on group brainstorming has identified social factors that may influence these processes such as production blocking (having to wait to express an idea because another person is talking), evaluation apprehension (fear of others' opinions of one's ideas) and social loafing (letting others do the work) [13]. In particular, even though brainstorming rules have attempted to reduce criticisms, evaluation apprehension and resulting self-censorship remains salient in brainstorming.

Evaluation apprehension during group brainstorming can be linked to more general social psychological processes like impression management and self-presentation that are driven by a desire for social acceptance [18]. Therefore, the extent of evaluation apprehension that one may exhibit is a function of the applicable social norms. Brainstorming instructions for eliminating evaluation concerns were shown to be ineffective [14]. If contributing unique ideas is considered socially acceptable in the setting (e.g., in particular cultures or media), the effectiveness of group brainstorming is likely to be enhanced. Culture and communicative medium may play key roles in determining the extent of evaluation apprehension people feel during group brainstorming.

Prior research on group brainstorming has focused extensively on productivity rather than on processes of communication and social interaction. Recent analyses of conversations recorded from group brainstorming sessions revealed that the underlying communicative processes were more complex than expected [24]. Thriving conversational activities were observed in the field. Although such conversation violates Osborn's normative brainstorming rules [36], it is popular in real world cooperative work. Currently there is very little understanding of the conversational aspects of brainstorming.

At least two dimensions of brainstorming conversations are of interest: (a) talkativeness-how engaged and productive group members are, and (b) responsiveness - the extent to which group members respond interactively to others' suggestions. Conversational responsiveness is an established concept in linguistic studies of dialogue structure [4]. Utterances in dialogues are often categorized as initiations versus responses. In ordinary dialogues, initiations set up discourse expectations, and responses fulfill these expectations. In group brainstorming conversations, an initiation (e.g., suggesting an idea) does not necessarily call for any response [24]. Decisions about whether or not to respond to another's idea are thus likely to be based on group norms, culturally-based conversational styles and similar factors.

\section{Dimensions of Cultural Variation}

Culture influences what social norms individuals recognize and what behaviors they believe they should or should not perform [44]. There has been much debate regarding how cultures differ from each other and what cultural dimensions can be used to explain observed cultural differences. Here we review three interrelated dimensions that are especially relevant to group brainstorming: individualism vs. collectivism [22][44], analytic vs. holistic reasoning [35] and low vs. high-context communication styles [21]. Because our goal is to understand internationally constituted brainstorming teams, we focus on "national culture," which we define as the central 
tendency among a set of people united by geographical borders and, therefore, a certain degree of shared heritage, language and practices. It should be stressed that we do not assume homogeneity within national cultures or view cultural differences as absolutes. Rather, we expect these cultural differences to be ones of degree or emphasis among a heterogeneous set of people.

Individualism-collectivism. Individualistic cultures, such as those of the U.S., Canada and Germany, value the autonomy of individuals in groups and emphasize personal gain. Collectivistic cultures such as those of China and Japan tend to view individuals as components of the group and focus on group goals [22][44]

In a brainstorming task, individuals from collectivistic cultural backgrounds may experience conflicting priorities between their cultural norms of harmony and conformity [44] and the typical instructions for brainstorming tasks, which call for active participation, divergent thinking and different perspectives [33]. This conflict could decrease collectivistic participants' willingness to contribute to group brainstorming sessions. In contrast, members of individualistic cultures, which value the expression of personal thoughts and ideas, particularly unique ones, may be quite willing to contribute to group brainstorming.

Analytic vs. holistic reasoning. Recent research found that members of East Asian cultures attended more to peripheral and contextual information [7][31][32] and reasoned holistically to take actions [31][35]. In contrast, Western participants tended to think analytically and attend to foreground information that appears important, overlooking peripheral and contextual information [7][31][32][35].

In the context of group brainstorming, the distinction between holistic and analytic reasoning may be evident in how sensitive participants are to social and contextual influences. Participants from holistic cultures may be more sensitive to contextual information during group brainstorming, including cues about other group members' cultural backgrounds and the discrepancy between self and others. For holistic thinkers, detecting or expecting cultural discrepancy in styles of communication and collaboration may lead to discomfort and a motivation to reduce the discrepancy by adapting their own actions and ideas to the rest of the group. In contrast, members of analytic cultures may focus more narrowly on the task at hand, ignoring and thus failing to adapt to social and cultural differences.

Low vs. high context communication. Hall [21] proposed that cultures varied in how and where speakers encoded information for communicating intended messages. He distinguished low-context and high-context communication patterns. Speakers in low-context cultures, such as that of the United States, tend to state messages verbally and explicitly. Speakers in high-context cultures, such as that of China, tend to use multiple channels (e.g., non-verbal cues) and the context (e.g., interpersonal relationships) to communicate the messages in an implicit manner [20].
Low vs. high context communicators may be expected to differ in how they ground their messages, or ensure that the message has been understood as intended by other group members ([5] [29]). Grounding may be undertaken by a number of means, such as asking questions verbally (e.g., "do you understand?") or seeking non-verbal evidence of comprehension from others' facial expressions or reactions. We might expect speakers from high-context cultures to place greater emphasis on nonverbal cues in the grounding process than speakers from low-context cultures. As a result, we would expect grounding to be more difficult for high context speakers when using leaner media such as IM or text chat than when using richer media such as video conferencing. However, prior work is inconsistent on this point (e.g., [38] [39] [45]).

In the context of group brainstorming, in which multiple team members may offer ideas at the same time, it can be cognitively expensive to form and maintain multiple conversational threads to ground multiple idea proposals interactively in parallel. Therefore, cultures may differ in how many details are provided for offered ideas. Participants from high-context cultures may provide less information because they rely on shared context to clarify their meaning. In contrast, participants from low-context cultures may tend to explicate their or others' ideas and may engage more in interactive grounding if necessary.

\section{Effects of Group Cultural Composition}

One interesting issue raised by intercultural collaboration concerns the influences of working in culturally homogeneous vs. heterogeneous groups. Research on small groups has revealed that interpersonal interactions within groups may influence group members' attitudes and behaviors [28]. Studies of communication accommodation also suggest that people adapt their communication patterns to those of their partners [19]. Therefore, we might expect cultural adaptation in reasoning and communication styles to occur in mixed-culture groups [3]. Consistent with this expectation, several recent studies have shown that bicultural individuals' cultural attribution and decisionmaking shifts according to cultural cues presented in the context [6][23]. Further, it is likely that the extent of this adaptation depends on whether the individual comes from an analytic vs. holistic culture. As we discussed earlier, members of holistic cultures may be more aware of contextual cultural cues and thus more likely to adapt to their partners.

There is relatively little research investigating the influence of group cultural composition on collaborative work by contrasting intra-cultural with intercultural groups [3]. More specifically, there is little understanding of whether the low and high context communication styles Hall identified are stable culturally-based characteristics of individuals or situation-specific strategies that shift depending on the cultural makeup of a brainstorming group. 


\section{Effects of Medium on Brainstorming}

Communication medium can regulate and even mask the social information that individuals perceive in communication [43], with subsequent effects on team interaction (see, e.g., the review in [42]). For example, a social norm such as "do not state one's wishes directly," salient in some high-context cultures, may appear more or less mandatory to individuals depending on the medium in use. Such medium-based expectations may affect the group brainstorming process, or interact with culture (from which the norms arise), or both.

Media richness refers to the capacity of a given medium to support the delivery and processing of multiple channels of information and enable a change of understanding within a time interval [10]. Rich and lean media differ in a number of ways, including the immediacy of feedback and the number of cues or channels utilized [10][11]. Richer media such as video conferencing may afford greater social presence, providing partners with greater awareness of each other's presence than leaner media such as text-based chat would allow [41]. In group brainstorming, high social presence is considered detrimental because a heightened awareness of other group members may lead to greater evaluation apprehension, which in turn may lead to selfcensoring of wild ideas and consequently, poorer outcomes. Prior studies have showed that anonymity bolstered group brainstorming production [8]. CMC technologies enforcing anonymity and parallel inputs may effectively address evaluation apprehension and production blocking in group brainstorming [9][17][26]. These findings, derived from earlier single-culture settings, imply that leaner media may better support group brainstorming.

\section{The Current Study}

In this study, we investigate the communication processes of intra- and intercultural groups brainstorming over CMC. We examine how individual cultural background, group cultural composition and medium affect participants' conversational talkativeness and responsiveness.

The study compares Chinese-born and American-born participants because these cultures have been shown to differ along cultural dimensions important to group brainstorming (individualism/collectivism, holistic/analytic reasoning, and high/low context communication). The study of teams constituted of American and Chinese members also has practical purposes given the rise of such collaborations in the real world workplace.

We conducted a laboratory study in which three-person groups performed two brainstorming tasks, one using a text-only chatroom and one using a video-enabled chatroom that showed a view of other group members' faces. We chose these two media so that we could hold the input method constant (typing) while adding richness via video.

The study was designed to test several hypotheses. In terms of talkativeness, we propose:
H1: American participants will provide more contributions to the brainstorming discussion than Chinese participants because there is a better culture-task fit between American individualistic cultural norms and task characteristics. Chinese participants will contribute less due to evaluation apprehension. Also Americans will tend to add more details to their ideas due to their low-context communication style.

H2: Text-only chat will elicit more contributions from participants than video-enhanced chat, because of lower concerns of evaluation over the lean medium.

H3: The effect of medium on contributions to the brainstorming discussion will be greater for Chinese participants than for American participants. Leaner media, because visual cues have been removed, may reduce Chinese collectivistic and holistic sensitivity to others' presence.

H4: In terms of cultural adaptation, Chinese participants will become more talkative when working in mixed-culture groups because awareness of their partners' divergent communication patterns will motivate them to eliminate the differences through adaptation.

In terms of conversational responsiveness, we propose the following hypotheses:

H5: American participants, compared to their Chinese counterparts, will be more responsive due to a low-context communication style. They will add in details to explicate their own and others' ideas and engage in interactive conversations to ground messages.

H6: The use of video will lead to increased responsiveness. The heightened sense of others' presence and interactivity will compel participants to respond to each other's messages.

H7: Similar to $\mathrm{H} 4$, Chinese participants will become more responsive when working in mixed-culture groups because of increased awareness about cultural differences in communication styles. They will attempt to eliminate the discrepancy through adaptation. American participants will not exhibit as much cultural adaptation.

We will also look at whether culture and medium interact to influence people's responsiveness.

\section{METHOD}

\section{Design}

Three-person groups were asked to perform two structurally similar brainstorming tasks, one via a text-only chatroom and one via a video-enhanced chatroom. American- and Chinese-born participants were assigned to one of four group compositions: three Americans (AAA), three Chinese (CCC), two Americans and one Chinese (AAC) and one American and two Chinese (ACC). Overall, the experiment was a 4 (group cultural composition) by 2 (medium) design. Group cultural composition was a between-subject manipulation. Media and brainstorming topics were within- 


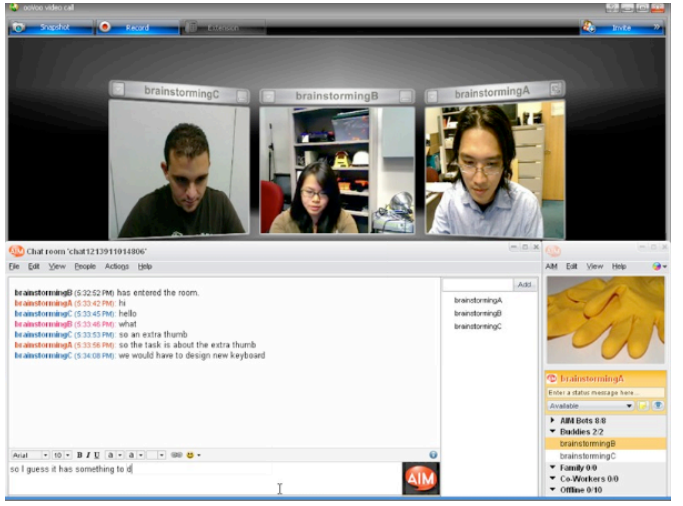

Figure 2. The video-enabled chatroom used in the study

subject manipulations and were counterbalanced to account for order effects.

\section{Participants}

Forty-eight participants were recruited from a U.S. university and surrounding community. Among them, 23 participants were Americans born in the U.S. with English as their first language. The remaining 25 participants were international students born in China (80\%), Hong Kong $(5 \%)$ or Taiwan $(15 \%)$ whose first language was Chinese. The Chinese participants were all fluent or nearly fluent in English. Although they were all currently studying at a U.S. university, the majority had been in the U.S. less than 2 years. Participants were randomly assigned to experimental conditions. A total of 16 brainstorming groups were formed (3 AAAs, 4 CCCs, 5 AACs, and 4 ACCs).

\section{Materials}

Two brainstorming tasks of equivalent difficulty were created: the "extra thumb" question and the "extra eye" question. The extra thumb question asked participants to generate ideas about the benefits and difficulties for people having a theoretical extra thumb on each hand in the future. This task has been used in many previous brainstorming studies [15][37]. The extra eye question (Figure 1 above) is a newly designed task that asked participants to generate ideas about the benefits and difficulties for people having an extra eye at the back of their heads in the future.

A post-experimental questionnaire was designed that included Triandis' individualism/collectivism scale [44] as well as basic demographic questions.

\section{Equipment}

In the text-only media condition, participants communicated via the chatroom function of AOL Instant Messenger (AIM, http://www.aim.com). In the videoenabled chatroom condition, participants were allowed to see themselves and the other two group members via a video conferencing client called ooVoo (http://www.oovoo.com) while using the same text chat client (see Figure 2). Audio was unavailable for both media conditions. Participants in both conditions worked on the brainstorming topics by typing into the text-based chatroom. At the right hand side of the computer display, a series of images related to the current brainstorming topic were shown as cues for participants' idea generation.

\section{Procedure}

Participants were brought to the laboratory and instructed about the brainstorming topics and brainstorming rules. Four conventional brainstorming rules [36] were provided to them: (a) the more ideas the better; (b) the wilder the ideas the better; (c) combination and improvement of ideas are sought; and (d) avoid evaluating others' ideas. Groups were given 15 minutes for each of the two brainstorming tasks. Between tasks, we switched which version of the chatroom they were using (text only or video enhanced text). At the end of both tasks, participants completed the post-experimental questionnaire.

\section{MEASURES}

The two sets of dependent measures, talkativeness and responsiveness, were derived from transcribing, processing and coding participants' conversations. We also analyzed participants' scores on the individualism/collectivism scale.

\section{Talkativeness}

Talkativeness was computed by counting the total number of words typed by each individual per brainstorming topic.

\section{Responsiveness}

To measure responsiveness, we first coded conversational turns by applying a coding scheme consisting of seven categories: ideation, meta-strategy, response, (dis)agreement, explanation, picture, and others. Table 1 shows the definitions and examples of the main categories in our coding scheme. Two independent coders were recruited to perform the coding task. Inter-coder reliability based on $6 \%$ of the data was satisfactory (Cohen's Kappa=.69).

Among the coding categories, two general genres were identified. Ideation and meta-strategy are active utterances featuring self-initiated contributions. They are proposals possibly initiating conversational threads and follow-up exchanges. On the other hand, response, (dis-)agreement and explanation are reactive or responsive contributions evoked and elicited by antecedents.

The measure of responsiveness is operationalized as the percentage of reactive utterances out of the total of active and reactive utterances:

\section{Responsiveness $=$ Number of Reactive Codes / (Number of Active Codes + Number of Reactive Codes)}

The higher the value, the more responsive a participant's messages are to the prior contributions by self or partners.

\section{Individualism and Collectivism}

Participants completed Triandis' individualism and collectivism scale [44]. The instrument consisted of 6 items for collectivism (Cronbach's alpha $=.47$ ) and 7 items for 
Table 1. Definitions and examples of main coding categories

\begin{tabular}{|c|c|c|c|}
\hline Category & Type & Definition & Example from Transcripts \\
\hline Ideation & Active & $\begin{array}{l}\text { Ideas offered for the first time in the } \\
\text { brainstorming session }\end{array}$ & $\begin{array}{l}\text { "(If having an extra eye,) I think it would be } \\
\text { harder to concentrate..." }\end{array}$ \\
\hline Meta-strategy & Active & $\begin{array}{l}\text { Strategizing, orienting and } \\
\text { coordinating brainstorming }\end{array}$ & "Any other ideas?" "What about privacy?" \\
\hline Response & Reactive & $\begin{array}{l}\text { Question, elaboration and opinion } \\
\text { evoked by previous contributions }\end{array}$ & $\begin{array}{l}\text { "(An idea about hard to concentrate was } \\
\text { introduced earlier) } \\
\text { Maybe people would close their third eye" }\end{array}$ \\
\hline (Dis-)Agreement & Reactive & $\begin{array}{l}\text { Acknowledgement and explicit } \\
\text { consent/dissent }\end{array}$ & "Ya, I agree with you" \\
\hline Explanation & Reactive & Explaining ideas & $\begin{array}{l}\text { "(An idea about hard to concentrate was } \\
\text { introduced earlier) } \\
\text { I know I have to not have things to look at if } \\
\text { I'm trying to study" }\end{array}$ \\
\hline Picture & $\mathrm{N} / \mathrm{A}$ & Talking about the peripheral pictures & $\begin{array}{l}\text { "Look at the pictures on the right of the } \\
\text { window. it seems that they are advertising } \\
\text { about what we are talking" }\end{array}$ \\
\hline
\end{tabular}

individualism (Cronbach's alpha $=.65$ ). We created a single composite score of individualism by averaging the scores on individualism items and the inverse scores on collectivism items.

\section{RESULTS}

The hypotheses and research questions were investigated by using mixed model ANOVAs to account for possible local interdependency between data points caused by repeated measures and social interactions in brainstorming groups [25]. Two linear mixed models were created for talkativeness and responsiveness, separately. Note that the talkativeness measure was positively-skewed; that is, the distribution had a long tail on the positive side because a few people talked quite a lot. Therefore, a $\log 10$ transformation was performed prior to analysis. An initial screening of the Chinese participants' data indicated no differences between those born in China, Taiwan, or Hong Kong for either talkativeness or responsiveness (both $F \leq 1$, $n s$.) Therefore, all native Chinese speakers were considered as a group in our analyses.

Attention was paid to whether prior acquaintance of participants affected group processes. From the postexperimental questionnaires, we identified four participants who knew each other before the study. A mixed-model ANOVA showed no significant difference on dependent measures (talkativeness, responsiveness) between participants from groups with or without a pre-existing relationship.

In the two linear mixed models, brainstorming trial was nested within the variable of participant. Participant was a random variable nested within group, and group was set as a random variable. Individual cultural background, communication medium, type of cultural group (e.g., working in same-culture versus mixed-culture group) and interactions among these variables were included as fixed effects in the models.

Note that in mixed models, when tests of fixed effects involve a linear combination of variances at different levels of the model (e.g., group and individual), it is standard to estimate the degree of freedoms associated with the denominators by using Satterthwaite's approximation. Therefore, non-integer degree of freedoms may occur in the analyses (see [30] for details).

\section{Talkativeness}

By using talkativeness as the dependent variable of a linear mixed model, we tested Hypotheses H1-4. The composite individualism score was included as a numeric covariate in this model for its role in hypotheses regarding talkativeness.

Consistent with Hypothesis H1, there was a main effect of culture on talkativeness. Participants with an American cultural background talked significantly more than those with a Chinese cultural background, $F[1,24.14]=8.27$, $p<.01$. Contrary to Hypothesis $\mathrm{H} 2$, there was no medium main effect.

The individualism score covariate also had a significant effect on talkativeness. The higher the individualism score, the more talkative a participant was (regression parameter $=.13, p<.05)$. Thus individual differences in individualism further refine the effect of individualistic vs. collectivistic national culture. 


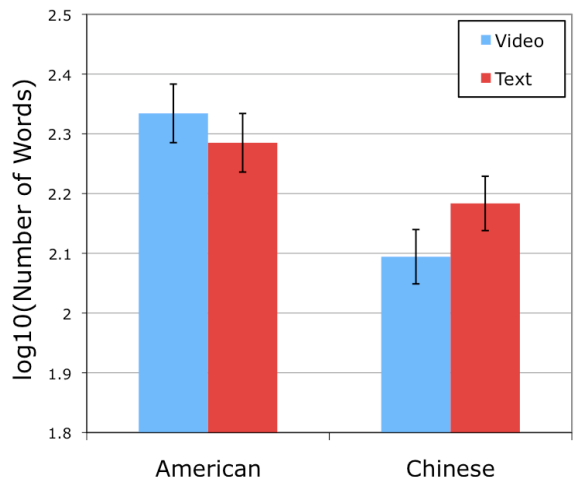

Figure 3. Talkativeness (logarithmically transformed) per trial by individual cultural background and media condition. Means and standard errors were estimated by the linear mixed model.

A mixed model analysis of the $\log 10$ transformed data showed a significant interaction between individual cultural background and medium $(F[1,44]=7.17, p<.05$; see Figure $3)$. Consistent with Hypothesis H3, post-hoc t-tests revealed that Chinese participants talked significantly more in the text-only chatroom than in the video-enabled chatroom $(t=2.52, p<.05)$. In contrast, there was no significant difference in talkativeness in the two media conditions for American participants. Also, it is interesting to note that in video-enabled chatrooms, American participants were more talkative than Chinese participants $(t=3.71, p<.01)$, but in the text-only condition, the difference between American and Chinese participants was not significant $(t=1.57, n . s$.). Leaner media thus appears to equalize talkativeness across cultural backgrounds.

Hypothesis H4 was not supported. There was no culture by type of cultural group interaction on talkativeness, suggesting no adaptation of this aspect of communication style as a function of the cultural homogeneity or heterogeneity of the group.

\section{Responsiveness}

We set responsiveness as the dependent variable of a linear mixed model to investigate Hypotheses H5-7.

Contrary to Hypotheses H5 and H6, there were no main effects of individual cultural background or communication medium on responsiveness. However, there was a significant interaction between individual cultural background and medium $(F[1,44]=5.45, p<.05)$. Post-hoc $\mathrm{t}$-tests showed that Americans were more responsive in the video-enabled chatroom than in the text-only chatroom $(t=2.07, \quad p<.05)$. Medium did not influence Chinese participants' responsiveness.

In support of $\mathrm{H} 7$, there was a significant individual cultural background by type of cultural group interaction $(F[1$, 21.06] $=4.23, p<.05)$. As shown in Figure 4, there was clearly cultural adaptation. When working in same-culture groups, Americans were the most responsive (on average,

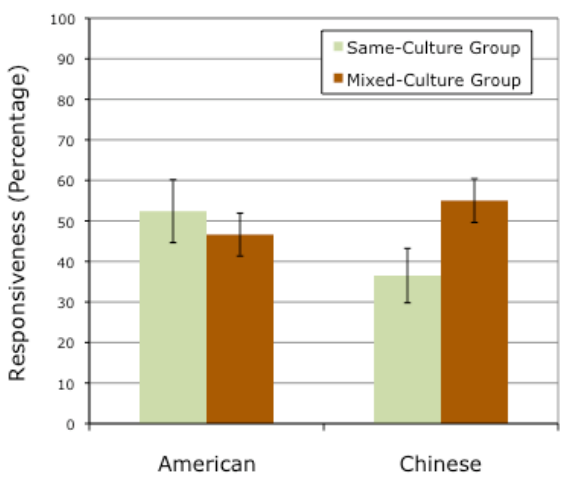

Figure 4. Responsiveness per trial by individual cultural background and type of cultural group. Means and standard errors were estimated by the linear mixed model.

$52 \%$ of their utterances were responsive) and Chinese were the least responsive (only $37 \%$ of their utterances were responsive). Interestingly, when working in a mixedcultural group, Chinese participants raised their level of responsiveness to that of the American participants $(55 \%$ of their utterances were responsive). Post-hoc tests revealed that the effect of cultural adaptation was significant for Chinese participants (Chinese-Same Culture Group versus Chinese-Mixed Culture Group, $t=2.15, p<.05)$. Although from Figure 4, it seems that Americans were lowering their responsiveness in mixed-culture groups, this effect was not significant.

\section{DISCUSSION}

The study has two key findings: (a) Culture by medium interaction-Chinese participants were less talkative in general, but they were more talkative in a text-only chatroom than a video-enabled chatroom. (b) Cultural adaptation-In same-culture groups, Americans were high in responsiveness while Chinese were significantly lower. When working in mixed-culture groups, Chinese participants adapted their responsiveness, increasing it to the level of the American participants. In this section, we discuss issues associated with these two findings.

\section{Culture by Medium Interaction}

In this study, we detected cultural background by medium interactions on both talkativeness and responsiveness, but there were no main effects of communication medium on either measure. This suggests that the influence of medium on brainstorming needs to be considered in light of the cultural backgrounds of the people using the system. Similarly, cultural differences in communication styles appeared to be adaptive in nature, thus appropriate technology adoption is required for better supporting collaborative work in multicultural contexts.

It is of interest to compare the current study with prior intercultural collaboration research. Prior studies using negotiation-oriented tasks found a reverse pattern on 
talkativeness. In [38], Chinese intracultural pairs talked more face-to-face (rich medium) than over text-only Instant Messaging (IM) (lean medium), while in the current study, Chinese talked more over a text-based medium than over a richer video-added medium. However, the previous study confounded input method (typing vs. speech) with richness, whereas we held input method constant across levels of media richness.

In [38], Chinese participants' talkativeness over rich medium seemed to be a consequence of seeking deeper contradiction resolution and cognitive agreements via prolonged discussions. This explanation is based on the observation that negotiation conversations are tightly coupled with the basic communication processes of conversational grounding. Talkativeness measures (e.g., number of words or number of turns conversed) are viewed as indicators of communication efficiency or efforts for achieving mutual understanding.

In contrast, in group brainstorming conversations, the role of conversational grounding remains unspecified. This is because (at least in principle) group brainstorming is a process of divergent thinking that seeks quantity of ideas, and it is not essential to follow others' ideas or to make sure ideas are understood as intended. Because group brainstorming calls for quantity of ideas rather than mutual understanding, normative brainstorming sessions are typically fast-paced, leaving little room for participants to work on grounding. For example, it is not unusual for group members in brainstorming sessions to be presented with several ideas almost simultaneously. Theoretically, it is too difficult for group members to converse deeply about every idea proposed. Therefore, the concept of communication efficiency or grounding does not seem compatible to normative group brainstorming. More words spoken may simply mean that more ideas are verbalized. However, as we have discussed at the beginning, group brainstorming conversations may be more complex than simply throwing out ideas [24]. For ideas to be stimulating and useful to other group members, they ought to be reasonably well understood. Grounding may still play a minimal role in group brainstorming, such as participants trying to achieve basic shared concepts, but not working hard to handle and repair misunderstandings. Overall, talkativeness in group brainstorming may be driven by multiple psychological processes, such as a combination of idea generation and grounding. The cross-study differences in talkativeness may be due to the different processes that drive people to talk in different tasks.

\section{Cultural Adaptation}

The interaction between cultural background and group cultural composition on responsiveness revealed that Chinese participants were more flexible in how they worked with partners in a group brainstorming session. The "holistic thinker" explanation can be applied on the grounds that Chinese-born participants are more sensitive to cultural cues and disposed to self-adapt in order to reconcile inconsistent communication styles existing in the sessions. In contrast, Americans appeared to have a more contextindependent pattern of collaboration. They may not have been aware of cultural differences in responsiveness, or may not have subscribed to a cultural norm indicating the need to "fix" this discrepancy through adaptation.

From the view of small group interaction, it may not be surprising that participants working in groups influence each other resulting in some mid-point between their individual communication styles [28]. But it is interesting that Chinese appeared to bear the brunt of this adaptation process. This is a noteworthy finding for intercultural collaboration. It merits further investigation to better understand the underlying psychological processes of cultural adaptation.

\section{Second Language Issue}

In the study, Chinese participants were non-native English speakers brainstorming in English. This enabled us to explore intercultural communication and collaboration but might also raise concerns that conversational styles and idea generation processes might differ for Chinese using their native language.

We found main effects of culture on talkativeness in the study. One explanation alternative to the discrepancy of cultural styles is the possible extra effort required in second language use by Chinese. However, this explanaton cannot account for the interaction effects between culture and medium on talkativeness as Chinese participants also conversed talkatively when using the text-only medium.

There is evidence showing that the cultural communication styles we identified are not peculiar to Chinese communicating in English. More specifically, the effects of typing in IM on Chinese communicating in a second language (English) [38] and in their native language (Chinese) [39] were found to be identical. One recent study found that Spanish-dominant English-Spanish bilinguals had similar idea generation productivity when brainstorming either in English or Spanish [2]. As one possible future direction to address the second language issue, we plan to replicate the study using American participants who are fluent in Chinese.

\section{Implications for Technology Adoption and Design}

Our findings have implications for technology adoption and for the design of systems. First, it is apparent that the same communication medium is not equally effective for members of all cultures. Seemingly small differences in features, such as adding video to a text-based chatroom, can significantly impact the extent to which members of some cultures contribute to group work.

Second, we found cultural adaptation in mixed-culture groups only for Chinese participants. American participants did not alter their behavior significantly in culturally 
heterogeneous vs. homogeneous groups. This finding may stem from the distinction between analytic and holistic reasoning. Perhaps American participants have less awareness of cultural differences in communication styles than their Chinese counterparts. An important question for future research is whether better performance on group brainstorming tasks would be achieved if both American and Chinese participants adapted their communication.

One design approach is to provide dynamic feedback to increase participants' awareness of cultural differences in communication styles and thus to distribute the responsibility of cultural accommodation to all members of mixed-culture teams. This type of dynamic feedback, which has been shown to improve group work in other contexts (e.g., [15], [27]) is a promising means of improving intercultural collaboration.

\section{CONCLUSION}

In this study, we investigated the influence of individual cultural background, group cultural composition and communication medium on group brainstorming conversations. Our focus was on conversational talkativeness and responsiveness. We found that although Chinese were less talkative in general, the use of lean medium increased Chinese participants' talkativeness. Interestingly, there was cultural adaptation such that Chinese participants became as responsive as Americans when working in mixed-culture groups. The findings demonstrate how cultural factors and medium jointly shape group brainstorming conversations.

\section{ACKNOWLEDGMENTS}

This material is based upon work supported by the National Science Foundation under Grants No. IIS-0803482, IIS0325047 and CNS-0551554. We thank Pablo-Alejandro Quinones, Ilana Diamant, Andy Echenique, Hau-yu Wong and Victoria Yew for their assistance in this project.

\section{REFERENCES}

1. Amabile, T. (1983). The social psychology of creativity: A componential conceptualization. Journal of Personality and Social Psychology, 45, 357-376.

2. Blot, K. J., Zarate, M. A., Paulus, P. B. (2003). Codeswitching across brainstorming sessions: implications for the revised hierarchical model of bilingual language processing. Experimental Psychology, 50(3), 171-183.

3. Bond, M. H. (2003). Cross-cultural social psychology and the real world of culturally diverse teams and dyads. In D. Tjosvold, \& K. Leung (Eds.). Cross-cultural management: Foundations and future. Burlington, VT: Ashgate Publishing Company.

4. Carletta, J., Isard, A., Isard, S., Kowtko, J. C., DohertySneddon, G., Anderson, A. H. (1997). The reliability of a dialogue structure coding scheme. Computational Linguistics, 23, 13-31.
5. Clark, H. H., \& Brennan, S. E. (1991). Grounding in communication. In L. B. Resnick, J. M. Levine, \& S. D. Teasley (Eds.), Perspectives on socially shared cognition (pp. 127-149). Washington, DC: American Psychological Association.

6. Cheng, C-Y., Lee, F., \& Benet-Martinez, V. (2006). Assimilation and contrast effects in cultural frame switching: Bicultural identity integration and valence of cultural values. Journal of Cross-Cultural Psychology, $37,742-760$.

7. Chua, H. F., Boland, J. E., \& Nisbett, R. E. (2005). Cultural variation in eye movements during scene perception. Proceedings of the National Academy of Sciences, 102, 12629- 12633.

8. Connolly, T., Jessup, L. M., Valacich, J. S. (1988). Effects of anonymity and evaluative tone on idea generation in computer-mediated groups. Management Science, 36, 689-703.

9. Connolly, T. (1993). Behavioral decision theory and group support systems. (pp.270-280). In L. Jessup \& J. Valacich (Eds.). Group support systems. NY: Macmillan.

10.Daft, R. L., \& Lengel, R. H. (1986). Organizational information requirement, media richness and structural design. Management Science, 32. 554-571.

11.Dennis, A. R., \& Valacich, J. S. (1999). Rethinking media richness: Toward a theory of media synchronicity. Proceedings of HICSS 1999.

12. Diamant, E. I., Fussell, S. R. \& Lo, F-L. (in press). "Where did we turn wrong?" Unpacking the effects of culture and technology on attributions of team performance. Proceedings of CSCW 2008. NY: ACM Press.

13.Diehl, M., \& Stroebe, W. (1987). Productivity loss in brainstorming groups: toward the solution of a riddle. Journal of Personality and Social Psychology, 53, 497509.

14.Diehl, M., \& Stroebe, W. (1991). Productivity loss in idea-generating groups: Tracking down the blocking effect. Journal of Personality and Social Psychology, 61, 392-403.

15.DiMicco, J.M., Pandolfo, A., \& Bender, W. (2004). Influencing group participation with a shared display. Proceedings of CSCW'04.

16. Dugosh, K. L., \& Paulus, P. B. (2005). Cognitive and social comparison processes in brainstorming. Journal of Experimental Social Psychology, 41, 313-320.

17. Gallupe, R. B., Dennis, A. R., Cooper, W. H., Valacich, J. S., Bastianutti, L. M.m \& Nunamaker, J F. (1992). Electronic brainstorming and group size. Academy of Management Journal, 35, 350-369.

18. Geen, R. G. (1991). Social motivation. Annual Review of Psychology, 42, 377-399. 
19. Giles, H., Coupland, J., \& Coupland, N. (1991). Contexts of Accommodation. New York, NY: Cambridge University Press.

20. Gudykunst, W. B., Matusmoto, Y., Ting-Toomey, S., Nishida, T., Kim, K., \& Heyman, S. (1996). The influence of cultural individualism-collectivism, selfconstruals, and individual values on communication styles across cultures. Human Communication Research, $22,510-543$.

21.Hall, E. (1976). Beyond Culture. New York, NY: Doubleday/Anchor Books.

22. Hofstede, G. (1983). Dimensions of national cultures in fifty countries and three regions. In J. Deregowski, S. Dzuirawiec \& R. Annis (Eds.), Explications in CrossCultural Psychology.

23.Hong, Y., Morris, M., Chiu, C., \& Benet-Martinez, V. (2000). Multicultural minds: A dynamic constructivist approach to culture and cognition. American Psychologists, 55, 709-720.

24. Jackson, M. H., \& Poole, M. S. (2003). Idea generation in naturally occurring contexts: complex appropriation of a simple group procedure. Human Communication Research, 29, 560-591.

25.Kenny, D. A., Mannetti, L., Pierro, A., \& Livi, S. (2002). The statistical analysis of data from small groups. Journal of Personality and Social Psychology, 83, 126-137.

26. Kerr, D. S., \& Murthy, U. S. (2004). Divergent and convergent idea generation in teams: A comparison of computer-mediated and face-to-face communication. Group Decision and Negotiation, 13, 381-399.

27.Leshed, G., Hancock, J.T., Cosley, D., McLeod, P.L., \& Gay, G. (2007). Feedback for Guiding Reflection on Teamwork Practices. Proceedings of Group'07.

28. Levine, J. M., \& Moreland, R. L. (1990). Progress in small group research. Annual Review of Psychology, 41, 585-634.

29.Li, H. Z., (1999). Grounding and information communication in intercultural and intracultural dyadic discourse. Discourse Processes, 28, 195-215.

30.Littell, R., Milliken, G. A., Stroup, W. W., \& Wolfinger, R. D. (1996). SAS system for mixed models. Cary, NC: SAS Institute.

31.Masuda, T., \& Nisbett, R. E. (2001). Attending holistically versus analytically: Comparing the context sensitivity of Japanese and Americans. Journal of Personality and Social Psychology, 81, 922-934.

32. Masuda, T., Ellsworth, P. C., Mesquita, B., Leu, J., Tanida, S., \& van de Veerdonk, E. (2008). Placing the face in context: Cultural differences in the perception of facial emotion. Journal of Personality and Social Psychology, 94, 365-381.

33. Nemeth, C. J., Personnaz, B., Personnaz, M., \& Goncalo, J. (2004). The liberating role of conflict in group creativity: A study in two countries. European Journal of Social Psychology, 34, 365-374.

34. Nijstad, B. A., \& Stroebe, W. (2006). How the group affects the mind: a cognitive model of idea generation in groups. Personality and Social Psychology Review, 10, 186-213.

35. Nisbett, R. E., Peng, K., Choi, I., Norenzayan, A. (2001). Culture and systems of thought: holistic versus analytic cognition. Psychological Review, 108(2), 291310.

36. Osborn, A. F. (1957). Applied imagination. New York: Scribner.

37.Paulus, P.B. Larey, T.S., Putman, V.L., Legget, K. L., \& Roland, E. J. (1996). Social influence processes in computer brainstorming, Basic and Applied Social Psychology, 18, 3-14.

38. Setlock, L D., Fussell, S. R., \& Neuwirth. C. (2004). Taking it out of context: collaborating within and across cultures in face-to-face settings and via instant messaging. Proceedings of CSCW 2004 (pp. 604-613), NY: ACM Press.

39. Setlock, L.D., Fussell, S. R., \& Shih, Y. Y. (2006). Effects of culture, language and communication medium on conversational grounding. Annual Meeting of the Society for Text and Discourse, Minneapolis, MN.

40. Setlock, L. D., Quinones, P. A., \& Fussell, S. R. (2007). Does culture interact with media richness? The effects of audio vs. video conferencing on Chinese and American dyads. Proceedings of HICSS 2007.

41. Short, J.A., Williams, E., \& Christie, B. (1976). The social psychology of telecommunications. NY: Wiley.

42. Spears, R., Lea, M. \& Postmes, T. (2001) Social psychological theories of computer-mediated communication: Social pain or social gain. In W. P. Robinson and H. Giles (Eds.) The New Handbook of Language and Social Psychology (pp. 601-623). Chichester: John Wiley \& Sons, Ltd.

43. Sproull, L., \& Kiesler, S. (1986). Reducing social context cues: Electronic main in organizational communications. Management Science, 32, 1492-1512.

44. Triandis, H. C. (1995). Individualism and Collectivism. Boulder, CO: Westview.

45. Veinott, E., Olson, J., Olson, G., \& Fu, X. (1999). Video helps remote work: Speakers who need to negotiate common ground benefit from seeing each other. In Proceedings of CHI 1999 (pp. 302-309). NY: ACM Press. 